\author{
Assistant Professor Mihaela MIHAI, PhD \\ The Bucharest University of Economic Studies \\ E-mail: mihaela.mihai@ csie.ase.ro \\ Professor Daniela MANEA, PhD \\ The Bucharest University of Economic Studies \\ Institute of National Economy \\ E-mail: daniela.manea@ csie.ase.ro \\ Professor Emilia TITAN, PhD \\ The Bucharest University of Economic Studies \\ Institute of National Economy \\ E-mail: emilia.titan@csie.ase.ro \\ Professor Valentina VASILE, PhD \\ Institute of National Economy \\ E-mail:valentinavasile2009@gmail.com
}

\title{
CORRELATIONS IN THE EUROPEAN CIRCULAR ECONOMY
}

Abstract. Circular economy is an economy based on the concept of circularity. Circularity means reuse, remanufacturing or recycling. The circular economy records higher economic benefits, but with minimal consumption of resources and less harmful to the environment. The economy is growing very fast, resources are limited, and the consequences are seen in the degradation of nature. So, the circular economy is the only solution to this issue facing society today. As the revenues are as bigger as possible, the intermediate consumption needs to be as small as possible. If revenues are expressed by gross domestic product, within the circular economy the link between $G D P$ and renewable resources must be direct, as the share of renewable energy grows, the GDP grows, too. Between GDP and unemployment rate there is an inverse correlation, and gas emissions are inversely proportional to renewable resources, when GDP grows, renewable energy grows, too, and unemployment rate and gas emissions are decreasing. For this, are analysed these variables for energy sector, using GDP per capita, the share of renewable energy, gas emissions and unemployment rate in relation to the active population. Starting from the theoretical concepts, an empirical model was created with these variables, showing the related link for Europe, over the 2007-2015 period, using panel analysis.

Keywords: Circular economy, Resources, Renewable energy, Recycling, GDP, Unemployment rate, Gas emissions.

JEL Classification: C13, C33, C51, H21, N74, 011.

DOI: $10.24818 / 18423264 / 52.4 .18 .05$ 
Mihaela Mihai, Daniela Manea, Emilia Titan, ValentinaVasile

\section{INTRODUCTION}

The forecasts show that the number of people on the planet will increase, leading to a global economy that needs more resources than we currently use. In our current, linear economy, about $80 \%$ of what we use is eliminated directly after use. Given the current situation, there is a need for an alternative to the current pattern of throwing, which leads to a circular economy (Planing, 2015).

Circular economy is a restorative economy, based on recycling, a balance between rapid economic growth and limitation of raw materials and energy ( $\mathrm{Su}$ and Zhou, 2005).

The ultimate goal of promoting circular economy is to establish a balance between economy, environment and society. The circular economy is viewed lately as a way to overcome the current pattern of production and consumption. There is a need for continuous growth, but not increasing the amount of resources, which implies increasing resource efficiency (Ghisellini et al., 2016).

Circular energy increases economic and social welfare. Economic welfare is measured by revenues, while social welfare is measured by a low unemployment rate. In this article, the circular economy is studied for energy sector, and the analysed variables are: GDP per capita, the share of renewable energy in total electricity, the level of gas emissions and the unemployment rate.

The circular economy involves minimal consumption and recycling, which means low intermediate consumption. If intermediate consumption is low, GDP is high, but if intermediate consumption decreases, renewable resources are rising. Economic theory establishes that there is an inverse correlation between GDP and unemployment rate, and when renewable resources are increasing the level of gas emissions is decreasing. For circular economy, when increase the renewable energy, the GDP increases, too and the unemployment rate and the level of the gas emissions decrease.

The economic theory establishes that there is an inverse link between GDP and unemployment rate, and with the increase in renewable resources, the level of gas emissions is decreasing. In the circular economy, the growth of renewable energy conduce to GDP growth, and unemployment rate and the level of gas emissions to decrease.

This article presents the results of a research that aims to establish a relationship between the variables describing the circular economy at European level in the period 2007-2015. In the first stage are determined the existing correlations between the variables, and in the second stage is established the relationship between them, highlighting the implications for the development of the circular economy. 


\section{REVIEW OF THE SCIENTIFIC LITERATURE}

Rapid economic development brings economic benefits, but also leads to waste generation and resource scarcity. Circular economy is the solution to these problems, balancing all three of the main aspects of the economy: environment, economic resources and benefits (Lieder and Rashid, 2016).

The concept of circularity is not a new one. In the past, circularity was represented by activities such as reuse, rebuilding or recycling. Circular economy means minimal resource consumption, with less harmful environmental effects, but with greater economic benefits.

The concept of circular economy was introduced by David Pearce in 1990 and represents the bridge between the economic functions of the environment (Andersen, 2006). In China, the circular economy was mentioned by scientists in 1998, but the government officially accepting it in 2002 (Zhu and Chertow, 2016).

This concept has the origin in the industrial ecological paradigm, especially in the German and Swedish environmental policies. They are based on closed cycles and are seen as a strategy to solve environmental problems arising from rapid economic development (Yuan et al., 2006).

Circular economy is the strategy of sustainable development and involves the efficient use of resources, i.e. low consumption, low emissions, but high performance. The circular economy is based on the $3 \mathrm{R}$ principle, which means reducing, reusing and recycling. Reducing refers primarily, to reducing the amount of raw materials, water and energy, secondly, to reducing unnecessary production, and thirdly, to reducing people's demand, but this does not means decreasing the quality of life. In essence, the circular economy is a cycle based on the reuse of resource-production-consumptionwaste, with the smallest resource, consumption and cost, to ultimately achieve maximum economic and social benefits (Li and Deng, 2011).

Waste recycling is the solution for the problem of industrial system sustainability. Significant progress has been made in Germany and Japan regarding recycling incentives in industrial systems, the benefits being visible. From this point of view, China goes beyond, implementing the circular economy principles, and circular economy becomes a national development objective. Mathews and Tan analyse and compare eco-industries initiatives in China with those undertaken in the West and in East Asia, showing the transformation of a straight economy into a circular economy is an evolution where the dynamic link are established gradually over time (Mathews and Tan, 2011).

China has experienced substantial economic growth, which is a real economic miracle, given its natural capital and environment. This increase was possible due to the fact that the circular economy was chosen as a national policy for sustainable development, by adopting national laws and regulations on it. China is the first country 
Mihaela Mihai, Daniela Manea, Emilia Titan, ValentinaVasile

to launch indicators on the circular economy. They are important to many policies and are decision-makers who can help achieving the objectives of the circular economy and revenue growth. The lack of these indicators is the lack of a comprehensive set of sustainability indicators, which should include social, business, urban/industrial symbiosis, absolute material/energy reduction and prevention-oriented indicators (Geng and $\mathrm{Fu}, 2012$ ).

In Dalian, China, the circular economy was implemented with the aim of conserving water, materials, energy and land and was a success (Geng and Zhu, 2009).

George, Lin and Chen present a theoretical model of circular economy, one with pollutant resources and one with recyclable resources. The results of the study indicate that the factors affecting economic growth are: the marginal product of recyclable factors, the recycling rate, the cost of using pollutant production factors and the level of pollution resulting from using pollutants. Unlike the Kuznets environmental curve, the results show an inverse link between environmental quality and economic growth. On the other hand, there is a direct link between the quality of the environment and the recycling ratio (George et al., 2015).

$\mathrm{Wu}$, Shi, Xia and Zhu analysed in China, for the period 2005-2010, the dynamics of circular economy efficiency through three characteristics: a) resource and pollutant reduction, b) waste reuse and resource recycling and c) pollution control and waste disposal. According to these characteristics, in the period 2005-2010, in China, the results show that the efficiency of the cyclical economy has increased slightly, which means that the circular economy policy had a significant effect. While resources and pollutants are reduced, waste reuse, resource recycling and pollution control and waste disposal are growing, between them is an inverse link (Wu et al., 2014).

Zhijun and Nailing propose the development of a scientific and effective evaluation system on the circular economy, with the aim of obtaining accurate information and improving guidance. This rating system should provide an overview and include economic development indices, green development indices and human development indices (Zhijun and Nailing, 2007).

Countries with high level of pollution also face a shortage of electricity. A solution to these two problems is the circular economy, i.e., renewable energy. As a result, a number of renewable energy policies, laws, and regulations have been issued in China, with the expectation that with the growth of renewable energy, environmental pollution will decline (Zhao et al., 2011).

Much of the total energy consumption is used in the manufacturing industries, with a large gap between energy demand and energy supply. The solution is energy conservation and renewable energy. As measures for this solution, policies and programs related to energy conservation were introduced in close connection with China's circular economic structure. Three branches have been studied to ensure the circular economy and energy conservation: the chemical industry, the metallurgical 
industry and the electricity industry. Technical solutions have also been sought, examining key technologies and research progress to make energy use more efficient, reduce energy consumption, and use disposal waste resources (Li et al., 2010).

In Germany, renewable energy is growing, and depending on fossil fuel prices, domestic facilities and international trade, global effects differ. However these variables will vary, their effect on employment is positive. Between these and the employment rate is a direct and strong link, which means that between them and the unemployment rate the link is inverse (Lehr et al., 2012).

The use of renewable energy contributes to reducing conventional energy consumption and, implicitly, to reducing carbon emissions. Given that renewable energy has grown in recent decades, China has also adopted policies, regulations and strategic plans related to renewable energy (Yuan et al., 2013).

$\mathrm{Li}$, Dong and others studied the continental China's circular economy between 1985-2007 and concluded that there is a positive link between energy consumption and economic growth, expressed by real GDP per capita. Over time, a $1 \%$ increase in real $G D P$ per capita increases energy consumption by about $0.48-0.50 \%$ and, therefore increases carbon dioxide emissions by about $0.41-0.43 \%$. (Li et al., 2011).

\section{RESEARCH METHODOLOGY}

Analysing the literature, we can conclude that the circular economy is described by economic and social welfare, low consumption, few waste. Economic welfare can be quantified through incomes, the social one through a low unemployment rate, low consumption through renewable resources, and waste through gas emissions. If we report the circular economy to the energy sector, we can correlate renewable energy with GDP, unemployment rate and gas emissions.

Given that Gross Domestic Product is the difference between Global Gross Product and Intermediate Consumption, if we reuse resources or produce with lowest consumption, GDP is increasing. As the circular economy brings economic benefits, the increase in incomes, i.e. GDP, will decrease the unemployment rate. As the link between $G D P$ and renewable resources is direct, and renewable resources are inversely proportional to gas emissions, we can expect that an increase in the share of renewable energy, will decrease the unemployment rate and gas emissions, and increase GDP.

The analysis is related to the 31 countries of Europe for the period 2007-2015 and the analysed variables are: GDP per capita, unemployment rate, gas emissions and the share of renewable energy. The data source is the Eurostat ${ }^{1}$ website, and the processing and analysis was performed with the statistical software EViews (version 9) and SPSS (version 21).

${ }^{1}$ http://ec.europa.eu/eurostat 
Mihaela Mihai, Daniela Manea, Emilia Titan, ValentinaVasile

$G D P$ is reported on the number of inhabitants, it is real, calculated in comparable prices.

The unemployment rate is calculated as a percentage, referring to the country's active population.

The share of renewable energy is calculated as the share of renewable energy in total energy consumption.

Noxes are greenhouse gas emissions, with the reference period the year 1990. This indicator shows the trends in total anthropogenic emissions from the greenhouse gas "Kyoto basket". It represents the total annual emissions in relation to 1990 emissions. The greenhouse gas "Kyoto basket" includes: carbon dioxide $\left(\mathrm{CO}_{2}\right)$, methane $\left(\mathrm{CH}_{4}\right)$, nitrogen oxide $\left(\mathrm{N}_{2} \mathrm{O}\right)$ and so-called fluorinated gases (fluorocarbons, perfluorocarbons), nitrogen trifluoride $\left(\mathrm{NF}_{3}\right)$ and sulphur hexafluoride $\left(\mathrm{SF}_{6}\right)$, which are aggregated in a single unit using global warming potential (GWP) for gas, equivalent $\mathrm{CO}_{2}$ units.

The purpose of the study is to determine whether there is a link between renewable energy, incomes, gas emissions and the unemployment rate, using empirical data.

For the analysis of renewable energy compared to other economic and industrial variables from a transversal and longitudinal perspective, it is proposed to use the panel data analysis.

The use of the panel model has the advantage of capturing important links between variables over time and of monitoring the unrealized individual effects of the pair of countries, allowing a generalized model (Davidescu et al., 2017).

A longitudinal study is one that collects data from subjects of the same sample over time. These studies are conducted in a wide variety of contexts and for a wide variety of purposes, but in many situations they have considerable analytical advantages over transversal studies. These advantages have been increasingly recognized and appreciated in recent years, resulting an increased number of longitudinal studies. This increase in interest occurred on governmental, academical and the private sector (Lynn, 2009).

Panel data is a set of cross-section data $Y_{i t}(i=1, \ldots$, nand $t=1, \cdots, T)$ obtained from statistical observation of the variables characteristic of a group of $n$ countries periodically, a defined time interval, T (Baltagi, 2005).

In panel data analysis, the following model for estimating the variation of a resultant variable according to the determinant factors is considered:

$$
y_{i t}=b_{0 i t}+b_{1 i t} x_{1 i t}+\cdots+b_{k i t} x_{k i t}+w_{i t}
$$

Notations:

$y_{i t} \quad$ the values of the dependent variable;

$x_{k i t} \quad-$ are the values of the independent variable, $X_{k}$, where: 
$i=1, \cdots, n-n$ representing the countries;

$t=1, \cdots, T-t$ representing the periods of time, respectively the years.

The $b_{0 i t}$ is a constant, $b_{k i t}$ is the estimates of the coefficients of the $X_{k}$, variables recorded for a country at time $t$, and $\mathrm{w}_{\mathrm{it}}$ is the estimated error (Sevestre, 2005).

If the $b_{k i t}$ coefficients are equal, the influence of the variables $X_{k}$ on the dependent variable is constant over time, which describes the existence of a homogeneity for the proposed model. If the $b_{k i t}$ coefficients are not equal,then the pattern is not homogeneous.

Because the number of coefficients $(n \cdot T \cdot(k+1))$ is greater than the total number of observations $(n \cdot T)$, the model is difficult to estimate based on traditional methods. Thus, four canonical models can be defined: fixed effects (individual and transversal), compound errors (random effects), compound coefficients and random coefficients (Jaba et al., 2013).

In the case of fixed effects model, fixed effects are eliminated by the least squares method (OLS), eliminating individual average values. Fixed effects $a_{i}$ are eliminated by extracting from the original model of the model corresponding to the individual media, i.e.:

$$
\left(y_{i t}-\bar{y}_{i}\right)=\left(x_{i t}-\bar{x}_{i}\right)^{\prime} \cdot b_{i t}+\left(w_{i t}-\bar{w}_{i}\right)
$$

In the case of the random effect model, the term $b_{0 i t}$ is included in the error term and is not correlated with the explanatory variables. Thus, the model is obtained:

$$
y_{i t}=x_{i t}^{\prime} \cdot b_{i t}+w_{i t}
$$

The random-effects model allows for the use of constant explanatory variables over time, but if the model had fixed effects, estimates would not be consistent (Aparaschivei, 2012).

The results in the fixed effect model lead to a consistent estimate even for the endogenous variable if the condition $x_{i t}$ it is not correlated with the variable time component of the error $w_{i t}$, but is correlated only with the inverse temporal component of the error $b_{0 i t}$ (Vasilescu, 2013).

The study considers models also with fixed and random effects, choosing the best. If the fixed-effect model is better, we assume that the influence of the factorial variables $\left(X_{k}\right)$ on the variable explained $(Y)$ is the same for all countries, regardless of the time period $\left(b_{k i t}=b_{k}\right)$, and the constant $\left(b_{0 i t}\right)$ can be decomposed as follows:

$$
b_{0 i t}=b_{0}+a_{i}+d_{t}
$$

Notations:

$b_{0 i t} \quad$ - represents the constant of the regression model; 
Mihaela Mihai, Daniela Manea, Emilia Titan, ValentinaVasile

$b_{0} \quad-$ a constant;

$a_{i} \quad-$ unobservable differences between countries, i.e. the individual effects or country specificity regarding renewable energy;

$d_{t} \quad-$ the time differences existing in a country, i.e. the fixed temporal effects or the existence of a temporal specificity in a country regarding renewable energy(Jabaet al., 2013).

Fixed Effect Models ( $F E$ ) apply when the intra-individual variation of variables is superior to inter-individual variation, otherwise random effect patterns $(R E)$ are applied. Hausman test statistics are used to test the fixed effects model. It shows that statistics:

$$
\frac{b(F E)-b(R E)}{\operatorname{var} b(F E)-\operatorname{var} b(R E)}
$$

is distributed $\chi^{2}$ with $\mathrm{k}$ degrees of freedom, with the error of rejecting the null hypothesis that considers the model with random effects being good (Menard, 2008).

Using the homogeneity test, the coefficients of the studied model are examined in a cross-sectional dimension and it is determined whether the model is unique for all studied countries. If there is a heterogeneity, it is considered that the use of panel data cannot be justified (Jabaet al., 2013).

For estimating the impact of GDP, gas emissions and unemployment rate on the share of renewable energy in European countries for 2007-2015 period, the following model with fixed effects is proposed:

$$
R E_{i t}=b_{0}+a_{i}+d_{t}+b_{1} G D P_{i t}+b_{2} U R_{i t}+b_{3} G E_{i t}+w_{i t}
$$

Notations:

$R E \quad-$ share of renewable energy,

GDP - GDP per capita, comparable prices, because GDP allows investment in renewable energy,

$U R$ - unemployment rate, because renewable energy replaces fossil energy and leads to a decrease in unemployment and

$G E \quad-$ gas emissions, the renewable energy implementation policy is achieved through green certificates and transactions with certificates of $\mathrm{CO}_{2}$. 


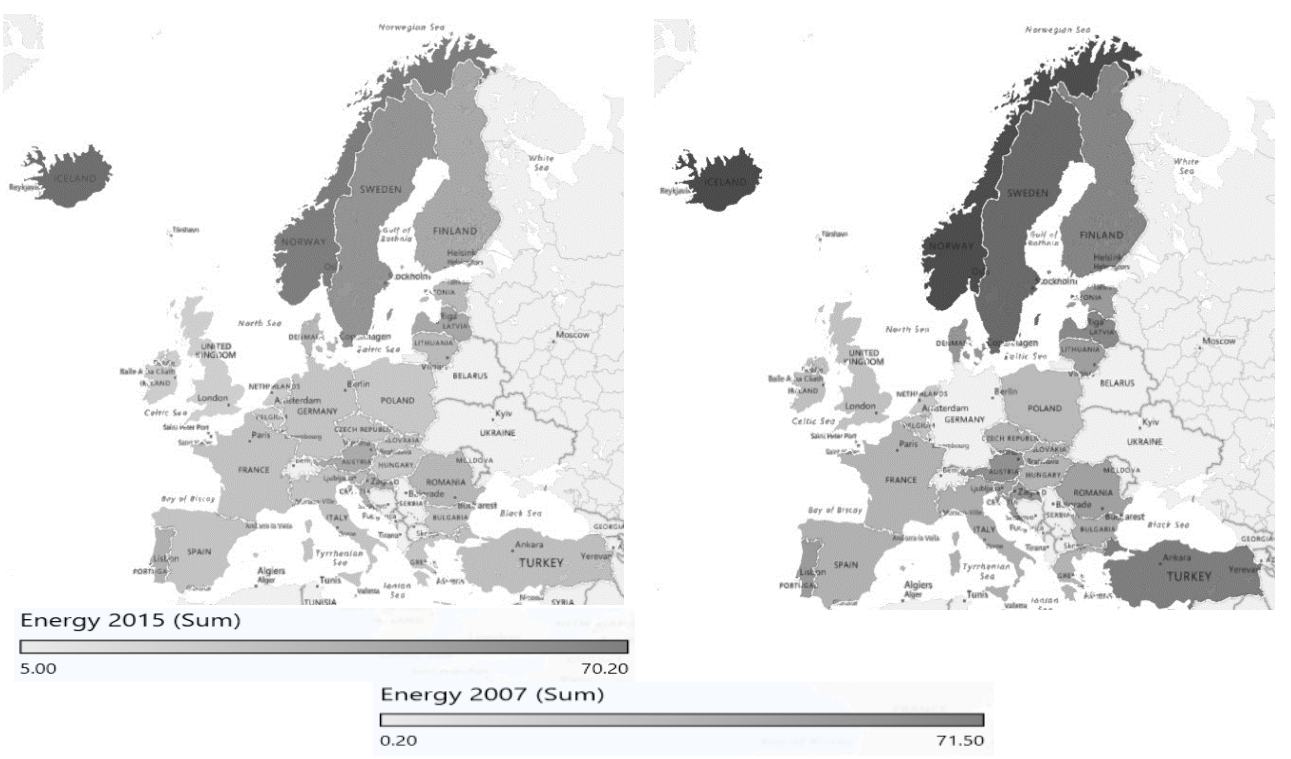

Figure 1:Europe map regarding renewable energy (2007 vs 2015)

Source: Own projection using Ms Excel

From the graphical representation of the share of renewable energy, one can see an increase in the share of all countries. This is mainly due to the implementation of circular economy policies at the European Union level, encouraging the use of renewable resources through various incentives, some of which are green certificates and certificates of $\mathrm{CO}_{2}$. A remarkable increase is observed in Turkey, with the share of renewable energy in 2015 rising more than three times over 2007. Although it is not part of the European Union, it has become aware of the need for this measure, taking into account the developed economy and high energy consumption.

\section{RESULTS AND DISCUSSIONS}

The Dendrogram shows that in 2007 the analysed countries were heterogeneous from the point of view of the variables analysed, and in 2015 they were uniformed, registering much smaller differences. If in 2007 Turkey forms a cluster with Cyprus and Spain, in 2015 Spain forms a cluster with Portugal and Austria, Cyprus and Turkey are different, with Turkey forming itself a cluster. 
Mihaela Mihai, Daniela Manea, Emilia Titan, ValentinaVasile

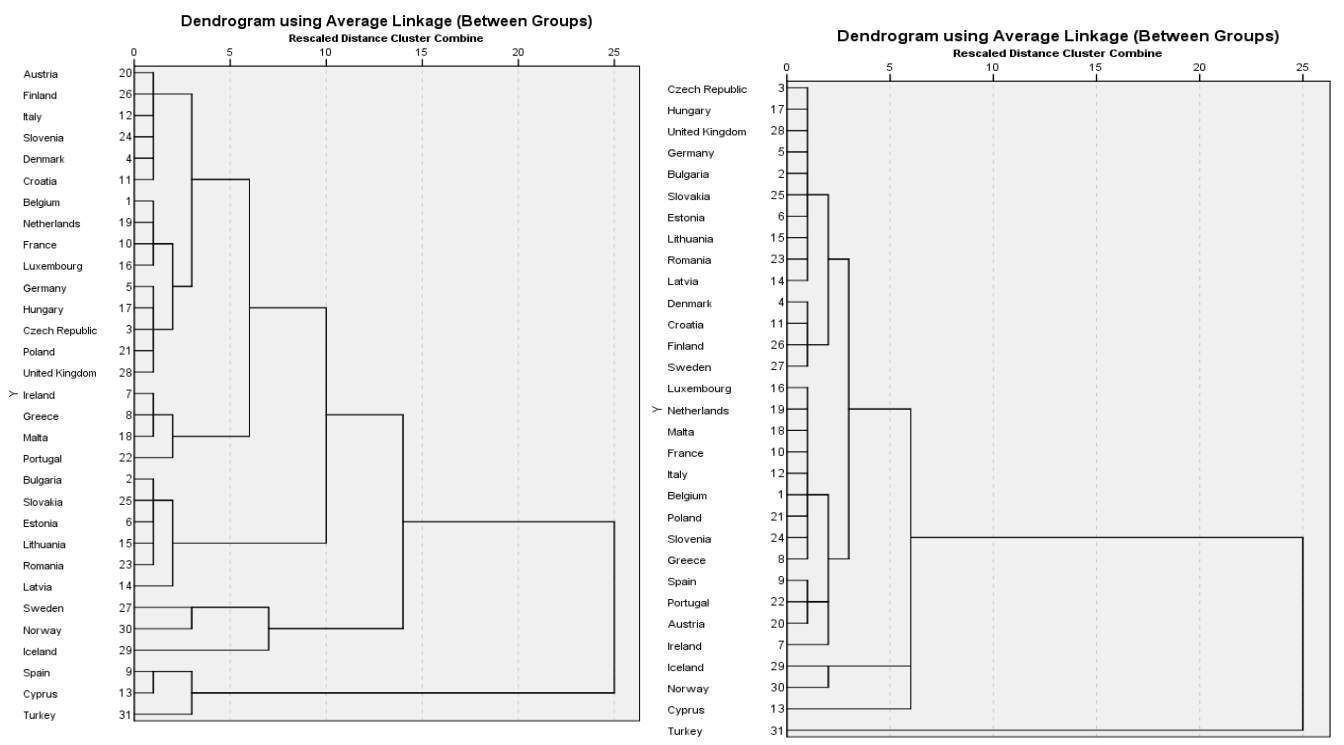

Figure 2:Dendrogram of countries in Europe regarding the analysed variables (2007 vs 2015)

Source: Own projection using SPSS

Figure 3 shows the dynamics of the analysed variables and it is observed that the trend is similar for all 31 countries over the entire period. However, the variable gas emissions is different from the others, recording much higher values. The variable gas emissions represents the volume of gas emissions reported to 1990, which means that over that period, the volume of noxes has increased greatly, much more than revenues or the share of renewable energy. Starting from this graph we can realise the necessity of circular economy, since the proportion of gas emissions and the other the variables is not balanced, the volume of emissions being much higher. 


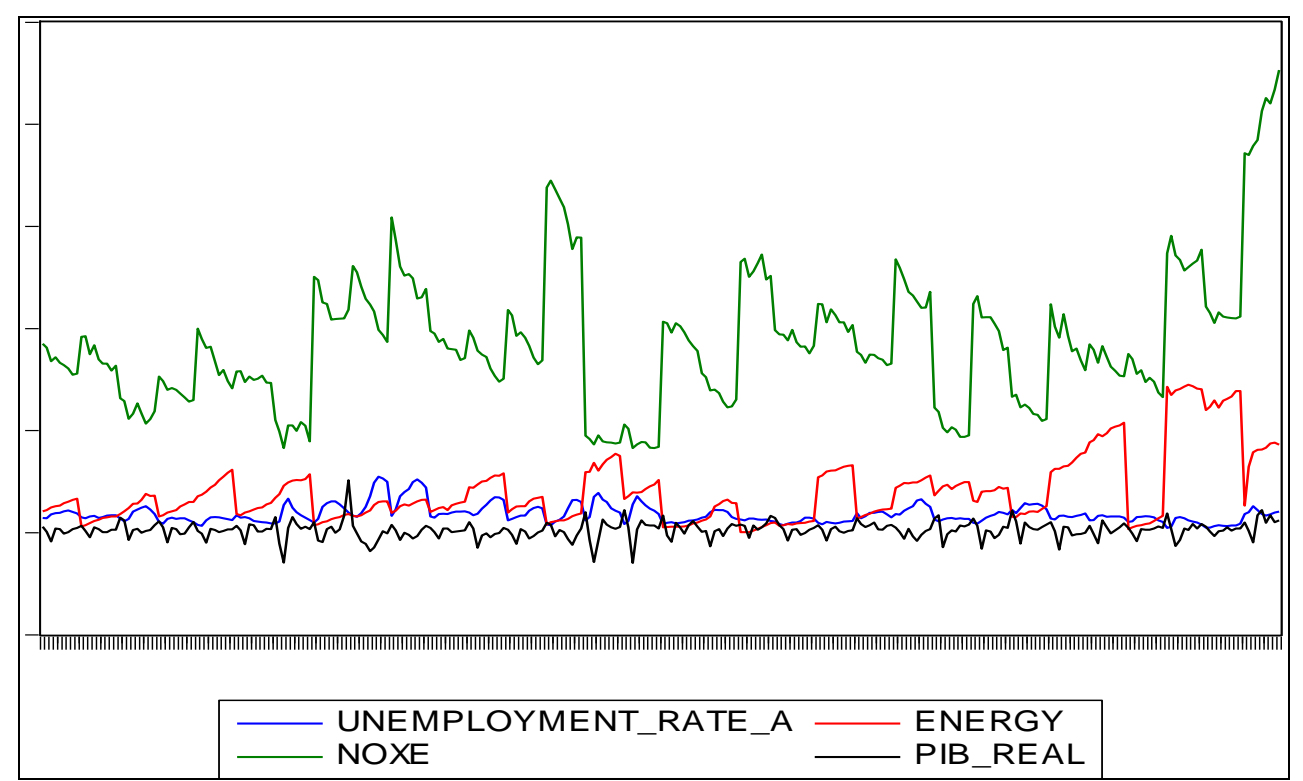

Figure 3: Dynamics of the considered variables (2007-2015)

Source: Own projection using EViews

According to Table 1, the strongest link for European countries is between GDP and unemployment rate, and the link is inverse, as we can see in the economic theory. There is also an inverse link between unemployment rate and share of renewable energy, the lower the share, the higher the unemployment rate. Between GDP and the share of renewable energy there is a direct link, when the share of renewable energy increases, GDP increases and the unemployment rate decreases.

\section{Table1: Correlation Matrix}

$\begin{array}{ccccc} & \text { UNEMPLOYMENT_RATE_A } & \text { PIB_REAL } & \text { NOXE } & \text { ENERGY } \\ \text { UNEMPLOYMENT_RATE_A } & 1 & -0.261096 & -0.183194 & -0.177483 \\ \text { PIB_REAL } & -0.261096 & 1 & 0.078747 & 0.002657 \\ \text { NOXE } & -0.183194 & 0.078747 & 1 & 0.145194 \\ \text { ENERGY } & -0.177483 & 0.002657 & 0.145194 & 1\end{array}$

Source: Own projection using EViews

To analyse the circular energy economy, the share of renewable energy, $E R_{i t}$, is used to analyse the panel data. It is estimated that the renewable energy $\left(E R_{i t}\right)$ from a transversal and longitudinal perspective, based on the model with fixed and random 
Mihaela Mihai, Daniela Manea, Emilia Titan, ValentinaVasile

effects, is influenced by unemployment rate, GDP and level of gas emissions. The main statistical results obtained in EViews for the fixed-effect model show whether the estimated model explains the variation of the resulting variable (renewable energy) and the validity of using of this model. The main statistics for the random effects model are shown in Table 2.

\section{Table 2: Influence of renewable energy (Random Effects Model)}

Dependent Variable: ENERGY

Method: Panel EGLS (Cross-sectionrandomeffects)

Date: 07/06/18 Time: 18:22

Sample: 20072015

Periodsincluded: 9

Cross-sectionsincluded: 31

Total panel (balanced) observations: 279

Swamy and Arora estimator of component variances

\begin{tabular}{|c|c|c|c|c|}
\hline Variable & Coefficient & Std. Error & t-Statistic & Prob. \\
\hline $\mathrm{C}$ & 29.70189 & 4.218907 & 7.040186 & 0.0000 \\
\hline NOXE & -0.122791 & 0.026974 & -4.552238 & 0.0000 \\
\hline PIB_REAL & 0.115335 & 0.044399 & 2.597714 & 0.0099 \\
\hline \multirow[t]{3}{*}{ UNEMPLOYMENT_RATE_A } & 0.251606 & 0.074386 & 3.382424 & 0.0008 \\
\hline & \multirow{2}{*}{\multicolumn{2}{|c|}{ Effects Specification }} & & \\
\hline & & & S.D. & Rho \\
\hline \multirow{3}{*}{$\begin{array}{l}\text { Cross-sectionrandom } \\
\text { Idiosyncraticrandom }\end{array}$} & & & 16.74196 & 0.9738 \\
\hline & & & 2.745478 & 0.0262 \\
\hline & \multicolumn{3}{|c|}{ Weighted Statistics } & \\
\hline R-squared & 0.208620 & \multirow{5}{*}{\multicolumn{2}{|c|}{$\begin{array}{l}\text { Mean dependent var } \\
\text { S.D. dependent var } \\
\text { Sum squaredresid } \\
\text { Durbin-Watson stat }\end{array}$}} & 1.122454 \\
\hline Adjusted R-squared & 0.199987 & & & 3.105668 \\
\hline S.E. of regression & 2.777816 & & & 2121.973 \\
\hline F-statistic & 24.16482 & & & 0.445989 \\
\hline \multirow[t]{2}{*}{ Prob(F-statistic) } & 0.000000 & & & \\
\hline & \multicolumn{3}{|c|}{ Unweighted Statistics } & \\
\hline \multirow{2}{*}{$\begin{array}{l}\text { R-squared } \\
\text { Sum squaredresid }\end{array}$} & -0.167261 & \multirow{2}{*}{\multicolumn{2}{|c|}{$\begin{array}{l}\text { Mean dependent var } \\
\text { Durbin-Watson stat }\end{array}$}} & 20.56487 \\
\hline & 93220.20 & & & 0.010152 \\
\hline
\end{tabular}

Source: Own projection using EViews 
Correlations in the European Circular Economy

Although all the coefficients are significant, we test whether the fixed-effect model is better with the Hausman test. The null hypothesis of the test states that the fixed-effect model estimates do not differ significantly from those of the randomeffects model. In our casesig $<0.05$, which means that we accept the alternative hypothesis, that is, the better model is the one with fixed effects.

You cannot use the pattern with random effects, as they may be correlated with the independent variables in the model.

Table 3: The Hausman Test (Fixed And Random Effects Model)

CorrelatedRandomEffects - Hausman Test

Equation: Untitled

Test cross-sectionrandomeffects

\begin{tabular}{lrrr}
\hline \hline Test Summary & Chi-Sq. Statistic & Chi-Sq. d.f. & Prob. \\
\hline \hline Cross-sectionrandom & 9.516500 & 3 & 0.0232 \\
\hline \hline
\end{tabular}

Cross-sectionrandomeffects test comparisons:

\begin{tabular}{ccccc} 
Variable & Fixed & Random & Var(Diff.) & Prob. \\
\hline \hline NOXE & -0.140239 & -0.122791 & 0.000070 & 0.0369 \\
PIB_REAL & 0.117685 & 0.115335 & 0.000001 & 0.0250 \\
UNEMPLOYMENT_RATE_A & 0.233326 & 0.251606 & 0.000199 & 0.1946 \\
\hline \hline
\end{tabular}

Source: Own projection using EViews

Based on $R$-Square, the fixed-effect model obtained from panel data analysis explains $97.68 \%$ of the renewable energy variation and is defined by unemployment rate, gas emissions and GDP.

The results obtained on the homogeneity hypothesis support the estimation of renewable energy based on unemployment, GDP and gas emissions in the case of fixed effects models.

Since the probability that a calculated $F$ (Fisher) test statistic is greater than its theoretical value is below the theoretical threshold of 0.0001 , the homogeneity assumption is accepted at the sample level. This shows that the renewable energy assessment model is unique and representative in all European countries included in the study (Jaba et al., 2013).

As the use of the fixed-effect model using the Hausman test has been validated, the impact of the unemployment rate, GDP and gas emissions on the share of renewable energy $\left(E R_{i t}\right)$ is similar for all countries, regardless the time period. 
Mihaela Mihai, Daniela Manea, Emilia Titan, ValentinaVasile

The results obtained from the estimation of renewable energy through the fixed-effect model show that unemployment rate, gas emissions and GDPsignificantly influence the share of renewable energy. According to the fixed-effect model, the regression equation for circular economy in energy sector to European countries during 2007-2015 can be written as:

$R E_{i t}=31.4962+a_{i}+d_{t}+0.117865 \cdot G D P_{i t}+0.233326 \cdot U R_{i t}+0.010239 \cdot G E_{i t}$

Notations:

$a_{i}-$ are the fixed effects determined by the individual size of the European countries (the share of renewable energy);

$d_{t}-$ represents the fixed effects determined by temporal dimension (the differences between years relating to the share of renewable energy).

Table 4: Influence of renewable energy (Fixed Effect Model)

Dependent Variable: ENERGY

Method: Panel LeastSquares

Date: 07/06/18 Time: 18:20

Sample: 20072015

Periodsincluded: 9

Cross-sectionsincluded: 31

Total panel (balanced) observations: 279

\begin{tabular}{|c|c|c|c|c|}
\hline Variable & Coefficient & Std. Error & $\mathrm{t}-$ Statistic & Prob. \\
\hline $\mathrm{C}$ & 31.49620 & 3.093855 & 10.18024 & 0.0000 \\
\hline NOXE & -0.140239 & 0.028240 & -4.965931 & 0.0000 \\
\hline PIB_REAL & 0.117685 & 0.044411 & 2.649903 & 0.0086 \\
\hline UNEMPLOYMENT_RATE_A & 0.233326 & 0.075709 & 3.081864 & 0.0023 \\
\hline \multicolumn{5}{|c|}{ EffectsSpecification } \\
\hline \multicolumn{5}{|c|}{ Cross-sectionfixed (dummyvariables) } \\
\hline R-squared & 0.976876 & \multicolumn{2}{|l|}{ Mean dependent var } & 20.56487 \\
\hline Adjusted R-squared & 0.973762 & \multicolumn{2}{|l|}{ S.D. dependent var } & 16.94917 \\
\hline S.E. of regression & 2.745478 & \multicolumn{2}{|l|}{ Akaikeinfocriterion } & 4.971561 \\
\hline Sum squaredresid & 1846.724 & \multicolumn{2}{|l|}{ Schwarz criterion } & 5.414075 \\
\hline Log likelihood & -659.5328 & \multicolumn{2}{|l|}{ Hannan-Quinn criter. } & 5.149074 \\
\hline F-statistic & 313.6401 & \multicolumn{2}{|l|}{ Durbin-Watson stat } & 0.511859 \\
\hline Prob(F-statistic) & 0.000000 & & & \\
\hline
\end{tabular}

Source: Own projection using EViews 
Correlations in the European Circular Economy

Errors are not correlated with each other, and the homoscedasticity hypothesis has been validated based on the Breusch-Pagan test, which records a sig $<0.05$ (Table 5).

\section{Table 5: Testing the errors}

Residual Cross-SectionDependence Test

Nullhypothesis: No cross-sectiondependence (correlation) in residuals

Equation: Untitled

Periodsincluded: 9

Cross-sectionsincluded: 31

Total panel observations: 279

Note: non-zero cross-sectionmeansdetected in data

Cross-sectionmeanswereremovedduringcomputation of correlations

\begin{tabular}{lccc}
\hline \hline \multicolumn{1}{c}{ Test } & Statistic & d.f. & Prob. \\
\hline \hline Breusch-Pagan LM & 1783.478 & 465 & 0.0000 \\
Pesaranscaled LM & 42.21807 & & 0.0000 \\
Pesaran CD & 23.74724 & & 0.0000 \\
\hline \hline
\end{tabular}

Source: Own projection using EViews

\section{CONCLUSIONS}

Economic development is influenced by the sufficiency of energy sources, so globalization and the need for safe energy and at reasonable costs are interlinked. As economies around the world have grown, energy demand has seen an upward trend.

In this context, this paper follows the evolution of some important macroeconomic indicators regarding circular economy in energy sector for European countries during 2007-2015 and conclude which variables affect the share of renewable energy, using panel data. A panel data model was used, analysing 31 countries in Europe.

The strongest link for European countries is between GDP and unemployment rate, and the link is inverse, as we find in economic theory. Between unemployment rate and share of renewable energy there is an inverse link, the lower the share, the higher the unemployment rate. Between GDP and share of renewable energy there is a direct link, when the share of renewable energy increases, GDP increases and unemployment rate decreases.

The econometric model has been estimated including all variables taken into account: unemployment rate, GDP/capita, gas emissions and share of renewable 
Mihaela Mihai, Daniela Manea, Emilia Titan, ValentinaVasile

energy. Statistical results have shown that, using panel data, the fixed-effect model for the study of renewable energy is relevant.

After it was concluded that the fixed-effect model was the best, the regression equation was obtained (7), it can be concluded that the share of renewable energy for European countries is explained by the economic variables considered in the analysis, so the share of renewable energy is influenced by the unemployment rate, GDP per capita and the emissions of gas.

Further research aims to extend the sample globally, but also to include other variables. In addition, depending on the possibilities of accessing the specific data series, the study can also be applied for the Romanian regions.

\section{REFERENCES}

[1] Andersen, M.S. (2006),An Introductory Note on the Environmental Economics of the Circular Economy; Sustainability Science, 2 (1), 133-140;

[2] Aparaschivei, L.(2012), Rata ocupării înRomânia. Analiză de tip panel (Occupancy Rate in Romania. Panel Data Analysis), Economie teoretică şi aplicată (Theoretical and applied economics), 7(572), 11-22;

[3] Baltagi, B. (2005),Econometric Analysis of Panel Data, 3rd Edition, West Sussex:JohnWiley\&Sons;

[4] Davidescu, A.A.M, Strat, V.A., Grosu, R.M., Zgură, I.D.(2017), Determinants of Romanians' Migration within the European Union: Static and Dynamic Panel Gravity Approaches; Amfiteatru Economic, 19(46), pp. 621-639;

[5] Dungaciu Dan, Cristea Darie, Dumitrescu Diana Alexandra, Pop Stefan Zaharie (2018), Stratfor vs. Reality (1995-2025). Dilemmas in Global Forecasting; Romanian Journal of Economic Forecasting, Volume 21, Issue 1/ 2018;

[6] Geng, Y., Fu, J.,Sarkis, J., Xue, B. (2012),Towards a National Circular Economy Indicator System in China: An Evaluation and Critical Analysis; Journal of Cleaner Production, 23 (1), 216-224;

[7] Geng, Y., Zhu, Q., Doberstein, B., Fujita, T. (2009),Implementing China's Circular Economy Concept at the Regional Level: A Review of Progress in Dalian, China; Waste Management, 29 (2), 996-1002;

[8] George, D.A.R., Lin, B.C.A, Chen, Y. (2015),A Circular Economy Model of Economic Growth; Environmental Modelling \& Software, 73, 60-63;

[9] Ghisellini, P., Cialani, C., Ulgiati, S. (2016),A Review on Circular Economy: The Expected Transition to a Balanced Interplay of Environmental and Economic Systems; Journal of Cleaner, 114, 11-32; 
Correlations in the European Circular Economy

[10] http://ec.europa.eu/eurostat;

[11] Jaba, E., Robu, I.B.,Balan, C.B., Robu, M.A. (2013),The Panel Data Analysis of Fraud Risk in Financial Auditing; Audit Financiar, 05, 25-36;

[12] Lehr, U., Lutz, C., Edler, D. (2012),Green Jobs? Economic Impacts of Renewable Energy in Germany; Energy Policy, 47, 358-364;

[13] Li, F., Dong, S., Li, X., Liang, Q., Yang, W. (2011),Energy ConsumptionEconomic Growth Relationship and Carbon Dioxide Emissions in China; Energy Policy, 39 (2), 568-574;

[14] Li, H., Bao, W., Xu, C., Zhang, Y., Xu, H. (2010),Energy Conservation and Circular Economy in China's Process Industries; Energy, 35 (11), 4273-4281;

[15] Li, X., Deng, B., Ye, H. (2011),The Research Based on the 3-R Principle of Agro-circular Economy Model-The Erhai Lake Basin as an Example; Energy Procedia, 5, 2011, 1399-1404;

[16] Lieder, M., Rashid, A. (2016). Towards Circular Economy Implementation: A Comprehensive Review in Context of Manufacturing Industry; Journal of Cleaner Production, 115, 36-51;

[17] Lynn, P. (2009),Methodology of Longitudinal Surveys. 1st Edition. Chichester: Wiley;

[18] Mathews, J. A., Tan, H. (2011),Progress toward a Circular Economy in China; Journal of Industrial Ecology, 15, 435-457;

[19]Menard, S. (2008),Handbook of Longitudinal Research: Design, Measurement, and Analysis. Burlington, MA:Academic Press;

[20] Mircea Constantin Scheau, Stefan Pop Zaharie(2017), Methods of Laundering Money Resulted from Cyber-crime. Economic Computation and Economic

Cybernetics Studies and Research; Volume 51; No. 3; ASE Publishing, Bucharest;

[21] Planing, P. (2015),Business Model Innovation in a Circular Economy Reasons for Non-acceptance of Circular business models; Open Journal of Business Model Innovation;

[22] Sevestre, P. (2002),Économetrie des données de panel, Paris: Dunod;

[23] Su, Y., Zhou, H. (2005),Promoting Circular Economy Development a Basic National Policy; NorthernEconomy, 1, 8-10;

[24] Vasilescu, M.D. (2013),Youth Labour Market Analysis; International Journal of Business and Management, 1, 37-57;

[25] Wu, H.Q., Shi, Y., Xia, Q., Zhu, W.D. (2014),Effectiveness of the Policy of Circular Economy in China: A DEA-based Analysis for the Period of 11th Fiveyear-plan; Resources, Conservation and Recycling, 83, 163-175;

[26] Yuan, X., Wang, X., Zuo, J. (2013), Renewable Energy in Buildings in ChinaA review; Renewable and Sustainable Energy Reviews, 24, 1-8;

[27] Yuan, Z., Bi, J., Moriguichi, Y. (2006),The Circular Economy: A New Development Strategy in China; Journal of Industrial Ecology, 10 (1-2), 4-8; 
Mihaela Mihai, Daniela Manea, Emilia Titan, ValentinaVasile

[28] Zhao, Z.Y., Zuao, J., Fan, L.L., Zillante, G. (2011),Impacts of Renewable Energy Regulations on the Structure of Power Generation in China-A Critical Analysis; Renewable Energy, 36 (1), 24-30;

[29] Zhijun, F., Nailing, Y. (2007),Putting a Circular Economy into Practice in China; SustainabilityScience, 2 (1), 95-101;

[30] Zhu, J., Chertow, M.R. (2016),Greening Industrial Production through Waste Recovery: “Comprehensive Utilization of Resources" in China; Environmental Science and Technology, 50 (5), 2175-2182. 